\title{
WHY USABILITY TESTING WORKS FOR IT AUDIT
}

\author{
Voraphan Manomuth Raungpaka, Kasetsart University, fbusvpr@ku.ac.th \\ Usana Patramontree, Kasetsart University, fbusunp@ku.ac.th
}

\begin{abstract}
This report is based on data from our usability study conducted to evaluate the internal control of an Information System at a Thai foundation. The main software, called Fund Management System (FMS), was developed in-house and was used to store and provide a management information system. In addition to administering the test data and the generalized audit package, we applied usability testing to gain better evidence on the users' aspect when using fund management system in specified tasks. This report aims to describe this new IT based technique and its performance when used in the auditing environment. This report shares what we found and what we think the related implications are for usability testing in IT audits, and the work of internal auditor. This can be seen as usability practice since the study results give direct input on how real users use the fund management system and results in discovery of mistakes that users make when using an interface of the fund management system software. Also, this paper uses the constructs of the Unified Theory of Acceptance and Use of Technology (UTAUT) (i.e., staff perceptions of software usefulness and ease of use, staff attitudes toward use, and behavioral intentions to use software) to evaluate staff acceptance of the fund management system software. Moreover, the study results show that staff acceptance of fund management system software is generally lower than what the system development team expected, and provides a quick and inexpensive way to gather general information about staff perceptions of fund management system software.
\end{abstract}

Keywords: Usability, Information Systems controls, Computer-Based Testing, Information Technology (IT)

\section{INTRODUCTION}

Fund Management System (FMS) is a pseudonym for the primary software of the information system of a foundation in Thailand. It has been in-house developed to store data for grant projects data, assist in managing the projects, and provide reports for management. Although FMS has many obvious advantages compared to the traditional manual

Volume XI, No. 1, 2010 system, there is a lively debate going on about the use of FMS.

We were contracted as outsourced experts to conduct the first audit of this information system, including of the IT Master Plan, software, and database on the behalf of the foundation's Internal Auditor Department. In our engagement plan, we were expected to perform normal Computer Assisted Audit techniques (CAATs) such as the test data and general audit software techniques. We also applied a usability testing in this audit engagement. From preliminary surveys, including an individual interview and a focus group, management and staff were quite satisfied about the various aspects of FMS, but there were also management and staff with negative experiences.

Although the IT system comprises hardware, software, dataware, and peopleware, more emphasis is on the infrastructure rather than the people, especially the user's side. After discovering weakness in accuracy and completeness of data, we usually suggest remedial actions regarding aspects of the IT technological process such as the System Development Life Cycle (SDLC) methodology. The impact of real users and computer interaction, especially when using a system interface on the data integrity, seems to have been overlooked or superficially commented on. In other words, how can an organization obtain a complete database when input data are incomplete in the first place? It is an obvious risk made in database integrity when input data are incomplete and/ or inaccurate because of mistakes that real users made when using an interface. And how can an auditor know? But auditors seldom know about any system usability problems of real users since auditors are hired to audit company's historical data. . This is our concern in applying the usability testing techniques to fulfill the gap between human and computer interaction in this audit job.

This report aimed to determine how to apply the usability testing in IT internal audit work and point out the appropriateness of using usability testing as a technology-based audit technique, especially to discover mistakes (i.e., inaccuracy and incompleteness) that users make when using a system interface to input data. We hope that our 
experience gained from this work can contribute beneficial knowledge to the profession worldwide.

\section{Usability Testing}

Usability testing is a technique used to evaluate a human-made product by testing it on users or acquiring direct information on how people use technology [7]. Research about usability testing has traditionally been from website designers' observations, web design, and Web Analytic research. They offer a compendium of website features, explore ways of making the website easier to use, and ways to reduce user error. Related Human-Computer Interaction research theories include cognitive theories and the minimal cognitive processing theory [5]. Usability testing focuses on measuring a man-made product's capacity to meet its intended purpose. Usability testing measures the usability, or ease of use, of a specific object or set of objects. During usability testing, the purpose is to observe people using the product to discover errors and areas for improvement. Usability testing involves watching people trying to use something for its intended purpose [8]. This can be seen as usability practice, since it gives direct input on how real users use the system or product and results in discovery of mistakes that users make when using an interface [7]. For example, in a typical usability test, quantitative data on participants' performance can be collected, participants' satisfaction with the product is needed and can be determined, and any usability problems that the product has can be identified [8]. Usability problems often occur when a user's mental model, the way a person believes a system works, does not match the actual workings of a system [16].

Usability testing generally involves measuring how well test participants respond in four areas: 1) Efficiency-how long does it take participants to complete basic tasks; 2) Accuracy - how many mistakes do participants make; 3) Recall-how much do the participants remember afterwards or after periods of non-use; and 4) Emotional response-how do the participants feel about the task completed?, Are the participants stressed?, Would they recommend this system to a friend? Also, usability testing assess another area call "Learnability"-how easy is it for users to accomplish basic task the first time they encounter the design [10]? Typically, the number of tasks completed successfully by the subject, length of time to complete the test tasks, number of errors, and time spent recovering from errors are measured. Currently, usability is an important aspect of IT products, such as software applications, web applications, computer interfaces, devices, or any other products $[8,11,13]$.

\section{Information Technology Controls and Auditing}

Recent works on IT controls and auditing research can be classified into two groups. The first group is on the compliance of IT governance, IT frameworks, and theory developments [1, 14, 15]. The second group is on the real-time continuous monitoring and assurance $[1,2,3,6]$. It becomes quite a significant problem to the internal auditing profession since new legislation and professional standards demand a higher level of proficiency and professional care. The revised standards of The Institute of the Internal Auditor [4] state the nature of Internal Audit Work in no. 2100 as "The internal audit activity must evaluate and contribute to the improvement of governance, risk management, and control processes using a systematic and disciplined approach" and no.1220A2 requires that "Internal auditors must have sufficient knowledge of key information technology risks and controls and available technology-based audit techniques to perform their assigned work". At present, many professional auditors are confronted with the IT skill shortage to perform their audit engagements [12].

\section{RESEARCH METHODOLOGY}

\section{Usability Testing Method}

We used the test session observation and a post test questionnaire to five users. Usability studies with 5 users will allow discovery of $85 \%$ of the original usability problems [9], so we recruited five staff members who were familiar with the use of computers and some other software applications for between 6 months to 3 years, but who had never trained nor used the FMS software application.

\section{Observation on Individual Usability Test Session}

In our study, users were tested one at a time. We brought the staff member to our computer laboratory to administer individual testing for a sixty-minute test session. In our pre-test briefing, we introduced him/her to the FMS software application. Then, we asked him/her to do the following ten specified tasks: 1) record the provided data to gain project ID;2) add organization's data; 3 ) make a letter for a reviewer; 4) update project information: approved budget; 5) update project information: job period; 6) approve project; 7) create summary report; 8) create contract; 9) print contract; and 10) complete project. 
We carefully observed him/her during the test and encouraged him/her to accomplish the tasks as much as possible within that sixty-minute time frame. Also, we required the participants to "think-aloud", a technique used to solicit participant feedback during this test. He/she was asked to describe out loud how he/she was attempting to complete each task as he/she worked on his/her tasks while we video recorded what the user said and did. In addition, we asked the user two questions: "What are the obstacles to the user accomplishing his/her tasks?" and "What do we change to remove those obstacles?" After participant completed all the tasks, we performed a critical-incident analysis by following up on the participant's actions/comments and asking questions to clarify comments made or to encourage the participant to continue describing his/her actions. We took notes of user comments and actions taken during the test. Finally, after finishing the test, the participant answered 20 questions about his/her overall impression of the FMS software. Each test was approximately 1 hour.

\section{Post-Test Questionnaire}

The scale items were developed using the theoretical foundation provided by [17] to measure user's opinions of the use of the FMS software. The constructs of the Unified Theory of Acceptance and Use of Technology (UTAUT) were used to create the post-test questionnaire. The questionnaire used a 7 point Likert scale (e.g., 1- 'extremely disagree' o 7'extremely agree') and contained questions regarding the experience that the participant had with the FMS software. This questionnaire consisted of six parts (i.e., performance expectancy, effort expectancy, attitude toward using, facilitating conditions, self efficacy, and behavior intention). The following 20 items were used: "I would find the FMS software useful in my job," "Using the FMS software enables me to accomplish tasks more quickly," "Using the FMS software increases my productivity," "If I use the FMS software, I will increase my chances of getting a raise," "My interaction with the FMS software would be clear and understandable," "It would be easy for me to become skillful at using the FMS software," "I would find the FMS software easy to use," "Learning to operate the FMS software is easy for me," "Using the FMS software is a bad/good idea," "The FMS software makes work more interesting," "Working with the FMS software is fun," "I like working with the FMS software," "I have the resources necessary to use the FMS software," "I have the knowledge necessary to use the FMS software," I could complete a job or task using the FMS software..., "..., if there was no one around to tell me what to do as I go," “..., if I could call someone for help if I got stuck," “..., if I had a lot of time to complete the job for which the software was provided," "..., if I had just the built-in help facility for assistance," "I intend to use the software in the next months," "I predict I would use the system in the next months."

\section{Data Collection}

We counted a task as successful (S) if the user found the correct answer. If the user gave a wrong (W) answer, or if he or she gave up $(\mathrm{G})$, we counted the task as unsuccessful.

\section{RESULTS}

\section{Observation Results}

Figure 1 and table 1 show the proportion of the users who did the tasks successfully. In summary, only forty-six percent of the users who did the tasks successfully compared to the fifty-two and one percent of give ups and wrong answers, respectively.

Usability Testing of 5 Users (Total tasks $=50$ )

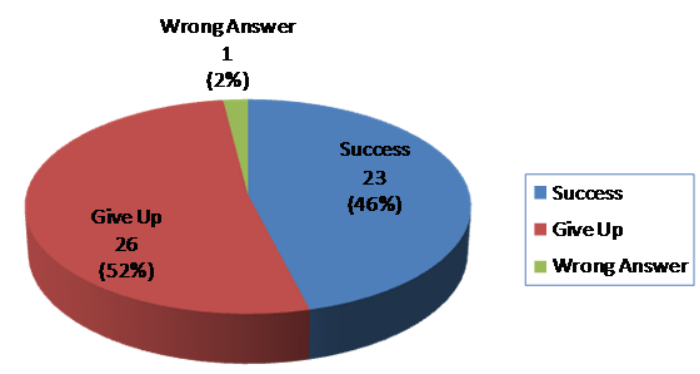

Figure 1. Proportion of how the users did the tasks

From our observations, the table 1 shows time the users spent on each task as well as total time the users spent on the ten tasks. In summary, the mean time is the average time that the users spent on each task. Also, the letters show that each user got the correct answer or success (S), wrong answer (W), or he/she gave up (G).

Figure 2 shows the results from the post-test questionnaire, the maximum, the minimum, and the mean score of all users' opinions in six areas. The study results show that staff acceptance of FMS software is generally lower than what the system development team expected. Users have rated high 
scores for performance expectancy, self efficacy, facilitating condition, and intention to use the software, whereas they provided lower scores for effort expectancy and attitude toward using. The results indicate that users accept that this FMS software is good for enhancing their performance, but they have low attitude toward using the FMS. For example, they disagree that the FMS software is easy to use and disagree that their interactions with the FMS software were clear and understandable. Therefore, more attention should be given in designing the software interface to make it easier to user and learn for real users in doing their jobs.

Table 1. Observation Results

\begin{tabular}{|c|c|c|c|c|c|c|c|c|c|c|c|c|c|c|c|}
\hline \multirow{3}{*}{\begin{tabular}{|c|} 
Task \\
No.
\end{tabular}} & \multicolumn{15}{|c|}{ Usability Tesing of the Fund Management System Users } \\
\hline & \multicolumn{2}{|c|}{ User \# 1} & \multicolumn{2}{|c|}{ User \# 2} & \multicolumn{2}{|c|}{ User \#3 } & \multicolumn{2}{|c|}{ User \#4 } & \multicolumn{2}{|c|}{ User \#5 } & \multicolumn{3}{|c|}{ How did they do the tasks? } & \multirow{2}{*}{\begin{tabular}{|l|} 
Total \\
Tasks
\end{tabular}} & \multirow{2}{*}{$\begin{array}{c}\text { Mean } \\
\text { Time }\end{array}$} \\
\hline & & \begin{tabular}{|l|}
$\begin{array}{l}\text { Time } \\
(\min .)\end{array}$ \\
\end{tabular} & & \begin{tabular}{|l|}
$\begin{array}{l}\text { Time } \\
\text { (min.) }\end{array}$ \\
\end{tabular} & & \begin{tabular}{|l|} 
Time \\
$(\min )$.
\end{tabular} & & \begin{tabular}{|l|}
$\begin{array}{l}\text { Time } \\
\text { (min.) }\end{array}$ \\
\end{tabular} & & \begin{tabular}{|l|} 
Time \\
$(\min )$.
\end{tabular} & Success & Give Up & \begin{tabular}{|l|} 
Wrong \\
Answer
\end{tabular} & & \\
\hline 1 & $\mathbf{s}$ & 6 & $\mathbf{s}$ & 15 & $\mathbf{s}$ & 9 & $\mathbf{s}$ & 30 & $\mathbf{s}$ & 9 & 5 & 0 & 0 & 5 & 13.80 \\
\hline 2 & $\mathbf{G}$ & 3 & $\mathbf{G}$ & 9 & $\mathbf{s}$ & 4 & G & 10 & G & 5 & 1 & 4 & 0 & 5 & 6.20 \\
\hline 3 & $\mathbf{w}$ & 22 & G & 5 & G & 13 & G & 7 & $\mathbf{G}$ & 8 & 0 & 4 & 1 & 5 & 11.00 \\
\hline 4 & $\mathrm{G}$ & 8 & G & 8 & G & 8 & G & 2 & $\mathbf{G}$ & 8 & 0 & 5 & 0 & 5 & 6.80 \\
\hline 5 & $\mathbf{s}$ & 3 & $\mathbf{G}$ & 9 & G & 9 & G & 13 & G & 8 & 1 & 4 & 0 & 5 & 8.41 \\
\hline 6 & $\mathbf{s}$ & 1 & $\mathbf{s}$ & 2 & s & 9 & $\mathbf{s}$ & 8 & $\mathbf{G}$ & 2 & 4 & 1 & 0 & 5 & 4.40 \\
\hline 7 & $\mathrm{~s}$ & 4 & $\mathbf{G}$ & 7 & $\mathrm{~s}$ & 10 & G & 2 & G & 6 & 2 & 3 & 0 & 5 & 5.80 \\
\hline 8 & $\mathbf{s}$ & 2 & $\mathbf{G}$ & 3 & $\mathbf{s}$ & 4 & G & 5 & $\mathbf{G}$ & 5 & 2 & 3 & 0 & 5 & 3.80 \\
\hline 9 & $\mathbf{s}$ & 2 & $\mathbf{G}$ & 2 & $\mathbf{s}$ & 1 & G & 9 & $\mathbf{G}$ & 1 & 3 & 2 & 0 & 5 & 3.00 \\
\hline 10 & $\mathbf{s}$ & 3 & $\mathbf{s}$ & 5 & $\mathbf{s}$ & 5 & $\mathbf{s}$ & 8 & $\mathbf{s}$ & 2 & 5 & 0 & 0 & 5 & 4.60 \\
\hline Total & & 54 & & 65 & & 72 & & 94 & & 54 & 23 & 26 & 1 & 50 & 6.78 \\
\hline \multicolumn{16}{|c|}{ Total Tasks $=50(100 \%)$ [ Success $=46 \%(23 / 50) ;$ Give Up $=52 \%(26 / 50) ;$ Wrong Answer $=2 \%(1 / 50)$ ] } \\
\hline Note: & $\mathbf{S}=$ & $=$ Succes & ss, c & G = Give & up, & $\mathbf{w}=\mathrm{Wro}$ & ong & Answer & & & & & & & \\
\hline
\end{tabular}

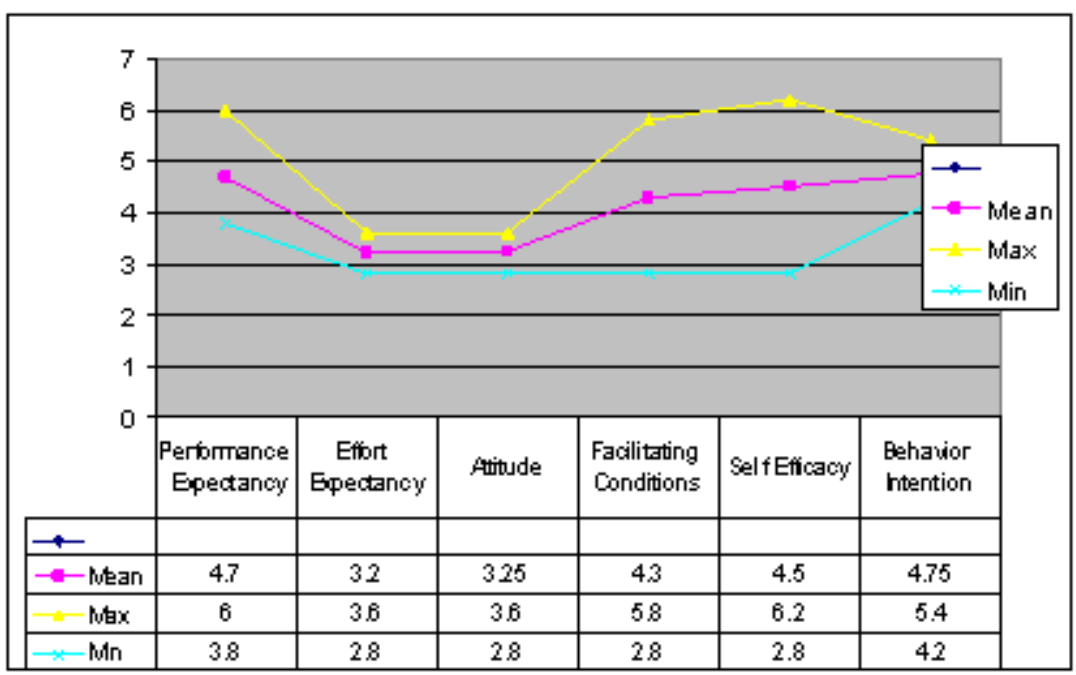

Figure 2. Results from Post Test questionnaire 


\section{CONCLUSIONS}

The number of users who did the tasks successfully, unsuccessfully, and who gave up shows the high risk level of inaccuracy and incompleteness of input data. The time spent on the test session shows the work efficiency which should not be over an average of 40 minutes. The mean time of 6.78 minutes shows the inefficiency in using this software.

\section{Recommendations}

There were many lessons learnt on this project:

- We found that usability testing provides important evidence on a significant component of the information system - the user. The usability testing technique is more crucial under the in-house or the customized software circumstance especially when the user acceptance test does not properly performed. Otherwise, it should be used as a supplementary audit technique in IT audits. The test is relatively easy to perform while its process is understandable by client's management and its result is easily accepted by the audittee.

- As a matter of fact, we found many mistakes and errors in this organization's database by conducting the generalized audit software and the test data method. With the usability testing, it gives us more information on users' behavior when using the application's interface, which we rarely had any explicit evidence before. Compared to the typical test data technique, the usability testing has provided more direct evidence from the users' testing under our auditor's observation.

- We also received the users' behavior attitude and recommendations from the 'think-aloud' protocols regarding the software problem. It is beneficial for further improvement of the product.

- In conclusion, we recommend the usability testing in the auditing environment and classify it as a computer assisted audit technique or a technology based audit technique.

\section{Practitioner's Take Away}

- Individual usability testing gives you more information on users' behavior when using the application's interface, which we rarely had any explicit audit evidence before.
- Individual usability testing supports thinking aloud method, which allows you to understand how participant thinks and feels about whatever he/she is looking at and doing, as he/she goes about his/her tasks.

- Individual usability testing gives you almost immediate feedback on your design and you will have much better understanding which parts of your interface are difficult to use.

- The video-recorded test session of the individual usability testing allows us to refer to what participant did and reacted so you can do an analysis of the video where the user identification of usability problems is emphasized.

- Individual usability testing session followed by a focused discussion enables us to clarify user's comments made during the test session.

- 'Zero users will give zero insights' (Nielsen, 200b), but the usability testing with only five users will allow you to discover more than $75 \%$ of the usability problems in the design.

\section{Acknowledgements}

Special appreciation is given to the Faculty of Business Administration, Kasetsart University, for their support.

\section{REFERENCES}

1. Boritz, E. (2005). IS practitioners' views on core concepts of information integrity International. Journal of Accounting Information Systems, 6(4), 260-279.

2. CICA/AICPA. (1999). Continuous auditing: Research report. Canadian Institute of Chartered Accountants.

3. Flowerday, S., Blundell, A.W., \& Von Solms, R. (2006).Continuous auditing technologies and models: A discussion. Computers \& Security, 25(5), 325-331.

4. Institute of Internal Auditors (IIA). (2008). Exposure draft international standards for the professional practice of internal auditing. Retrieved on March 5, 2009. Available: www.theiia.org/ Guidance 
5. Manomuth, V. (2006). An empirical test of the minimal cognitive processing theory of web buyer behavior. Unpublished Doctoral Dissertation, Utah State University, Logan.

6. Murthy, U. \& Groomer, M. (2004). A continuous auditing web services model for xml-based accounting systems. International Journal of Accounting Information Systems, 5 (2), 139-163.

7. Nielsen, J. (1994). Usability engineering. San Diego, CA: Morgan Kaufmann.

8. Nielsen, J. (2000a). Designing Web Usability. Indianapolis, In.: New Riders Publishing.

9. Nielsen, J. (2000b). Why you only need to test with 5 users. Retrieved on Jan 25, 2009. Available: www.useit.com/alertbox/20000319.html

10. Nielsen, J. (2003). Usability 101: Introduction to usability. Retrieved Jan 25, 2008, Available: www.useit.com/alertbox/20030825.html

11. Norden, L., Creelan, J. M., Kimball, D., \& Quesenbery, W. (2006). The machinery of democracy: Usability of voting systems. New York: Brennan Center of Justice at NYU School of Law.

12. Robert, L. (2003). Towards a paradigm for continuous auditing. Retrieved on Feb 07, 2009. Available: webcache.googleusercontent.com/search ?=cache:IkrtU7LxXVQJ:www.auditsoftware.net/c ommunity/how/run/tools/Towards\%2520a\%2520P aradigm $\% 2520$ for $\% 2520$ Continuous $\% 2520$ Auditin
1.doc+Towards+a+paradigm+for+continuous+audi ting\&cd $=1 \& \mathrm{hl}=$ en $\& \mathrm{ct}=\mathrm{clnk} \& \mathrm{gl}=$ th

13. Redish, J. (2007). Expanding usability testing to evaluate complex systems. Journal of Usability Studies, 2(3), 102-111.

14. Trites, G. (2004). Director Responsibility for IT governance. Retrieved on Jan 20, 2009. Available: www.sciencedirect.com/science?_ob= ArticleURL\&_udi=B6W6B-4CS4FMS-\&_user=10 \&_coverDate $=07 \% 2 \mathrm{~F} 31 \% 2 \mathrm{~F} 2004 \&$ rdoc $=1 \&$ fmt =high \&_orig $=$ search $\&$ _sort $=\mathrm{d} \&$ _docanchor $=\&$ vie $\mathrm{w}=\mathrm{c} \& \_$searchStrId $=1360084478 \&$ \&rerunOrigin $=\mathrm{g}$ oogle\&_acct $=$ C000050221\&_version $=1 \&$ \&urlVers ion $=0 \&$ _userid $=10 \& \mathrm{md} 5=82 \mathrm{a} 58 \mathrm{e} 6 \mathrm{e} 82 \mathrm{df0c} 725 \mathrm{ea} 4$ $00445 \mathrm{fb} 40 \mathrm{a} 9 \mathrm{f}$

15. Tuttle, B. \& Scott, V. D. (2007). An empirical examination of COBIT as an internal control framework for information technology. International Journal of Accounting Information Systems, 8(4), 240-263.

16. Van Duyne, D. K., Landay, J. A., \& Hong, J. I. (2003). The design of sites: Patterns, principles, and processes for crafting a customer-centered Web experience. San Francisco: Addison Wesley.

17. Venkatesh, V., Morris, M.G., Davis, G.B., Davis, \& F.D. (2003). User acceptance of information technology: Toward a unified view. MIS Quarterly, 27(3), 425-478. 